\title{
The Effect of Epidermal Structures on Leaf Spectral Signatures of Ice Plants (Aizoaceae)
}

\author{
René Hans-Jürgen Heim ${ }^{1}{ }^{*}$, Norbert Jürgens ${ }^{1}$, André Große-Stoltenberg ${ }^{2}$ and Jens Oldeland ${ }^{1}$
}

Received: 1 October 2015; Accepted: 6 December 2015; Published: 15 December 2015

Academic Editors: Eyal Ben-Dor, Clement Atzberger and Prasad S. Thenkabail

1 Biodiversity Ecology and Evolution of Plants, Biocenter Klein Flottbek and Botanical Garden, University of Hamburg, Ohnhorststraße 18, 22609 Hamburg, Germany;

norbert.juergens@uni-hamburg.de (N.J.); jens.oldeland@uni-hamburg.de (J.O.)

2 Institute of Landscape Ecology, Heisenbergstraße 2, 48149 Münster, Germany; andre.grosse-stoltenberg@uni-muenster.de

* Correspondence: rene.h.j.heim@googlemail.com; Tel.: +49-40-42816-407 or +61-415-311804

\begin{abstract}
Epidermal structures (ES) of leaves are known to affect the functional properties and spectral responses. Spectral studies focused mostly on the effect of hairs or wax layers only. We studied a wider range of different ES and their impact on spectral properties. Additionally, we identified spectral regions that allow distinguishing different ES. We used a field spectrometer to measure ex situ leaf spectral responses from $350 \mathrm{~nm}-2500 \mathrm{~nm}$. A spectral library for 25 species of the succulent family Aizoaceae was assembled. Five functional types were defined based on ES: flat epidermal cell surface, convex to papillary epidermal cell surface, bladder cells, hairs and wax cover. We tested the separability of ES using partial least squares discriminant analysis (PLS-DA) based on the spectral data. Subsequently, variable importance (VIP) was calculated to identify spectral regions relevant for discriminating our functional types (classes). Classification performance was high, with a kappa value of 0.9 indicating well-separable spectral classes. VIP calculations identified six spectral regions of increased importance for the classification. We confirmed and extended previous findings regarding the visible-near-infrared spectral region. Our experiments also confirmed that epidermal leaf traits can be classified due to clearly distinguishable spectral signatures across species and genera within the Aizoaceae.
\end{abstract}

Keywords: Aizoaceae; biophysical properties; leaf epidermis; field spectrometry; hyperspectral classification; leaf traits; optical types; plant functional types; succulent plants

\section{Introduction}

The leaf epidermal anatomy, together with its biochemical and biophysical properties, strongly controls the functional properties and the adaptive fitness of plants. Leaf optical properties depend on the leaves' biochemical and biophysical properties. Optically-measured spectral signatures of leaves are commonly used for analyzing these properties. For example, spectral signatures were used to measure biochemical components, such as pigment concentration [1,2] nutrient content [3] or other biochemicals, such as tannins [4,5]. Cellular leaf structure [6] or leaf water content [7] are typical biophysical properties of leaves that can be captured by spectral signatures. Although epidermal structures (ES) are known to affect the spectral signatures of leaves [8-10], they were mostly neglected in recent studies of leaf optical properties.

Already in the 1970s and 1980s, spectral properties of leaf ES, in particular hairs and glaucous waxes of desert plant species, were extensively studied [11-13]. The ecological function of ES-like hairs relates to the regulation of transpiration and to increasing the reflectance by up to $70 \%$ of the incoming radiation between $400 \mathrm{~nm}$ and $700 \mathrm{~nm}$; this results in a significant decrease of heat 
load compared to glabrous leaves under similar conditions [9]. While the effect of pubescence seems reasonably studied, little is known about the effects of other ES, such as bladder cells and papillary epidermal cells. The state of the art in the 1980s was limited to a spectral range of $1100 \mathrm{~nm}[11,14]$. Today, spectral analysis can range from $450 \mathrm{~nm}-2500 \mathrm{~nm}$. While wavelengths up to $700 \mathrm{~nm}$ are typically reflected by plant pigments, spectral regions beyond the NIR, i.e., the short wave infra-red (SWIR), contain information on biochemical compounds, such as lignin, cellulose and leaf water [15-17]. Yet, few studies of these spectral regions with regard to ES are available [18].

Epidermal structures of leaves can be highly diverse in arid ecosystems. In these habitats, the epidermis controls the interaction between the living plant and a harsh environment with extreme values of heat, radiation and very low air humidity [19]. In southwestern Africa, one of the few arid hot-spots of biodiversity on this planet [20], the ice plant family (Aizoaceae) developed a remarkable range of epidermal structures [21]. The Aizoaceae contain 2271 accepted species within 146 genera [22]. Members of the family are dominant in the vegetation in parts of South Africa and Namibia, with regard to biomass and the number of taxa [23]. Ihlenfeldt and Hartmann [21] and Jürgens [23] developed a typology, which was extended by Niesler [24] to finally include eight different types of ES occurring within the Aizoaceae (e.g., big hetero-cellular bladder cells, big papillate hetero-cellular bladder cells, homo-cellular types and hybrid forms). This diversity of ES within one plant family from the same bioclimatic region makes the Aizoaceae an interesting object to study the effects of ES on spectral signatures. A choice of species with a close evolutionary relationship helps to ensure that spectral responses of the sample differ not just due to the line of evolutionary development. An approach such as this has not been conducted with a phylogenetically close set of species thus far.

Many recent studies showed that it is possible to distinguish between plant species based on their spectral signatures [25-27]; even cultivars of tea [28], wine [29] or other commercially-relevant crops [30] were spectrally distinguished. However, in all of these cases, the species were a priori known and either physiologically or evolutionary different; these conditions strongly facilitate the separation of spectral responses. Ustin and Gamon [31] argued that it would make more sense to treat plant species or, more precisely, spectrally-measured vegetation canopies as "optical types". This term was coined in relation to the idea of plant functional types [32] and recently revisited in very comprehensive reviews $[33,34]$. Epidermal structures could play an important role in defining Ustin and Gamon's optical types.

In this study, we: (i) test whether Aizoaceae with similar epidermal types share similar spectral responses; (ii) apply a spectral classification in order to test whether different epidermal types are indeed spectrally distinguishable; and (iii) test which spectral regions, e.g., full, VIS, NIR, SWIR I and SWIR II, are most suitable for separating and classifying epidermal types (ETs) based on epidermal structures (ES). In a condensed expression, we want to test if ETs are similar in their spectral properties within an ET and if they significantly differ between other ETs.

\section{Experimental Section}

\subsection{Sample Collection}

The botanical garden, administrated by the University of Hamburg/Germany, hosts a large living collection of Aizoaceae with several hundred species from 82 genera. We used this living collection as a foundation to sample spectral signatures. Leaves of Aizoaceae species (Table 1) were surveyed ex situ with a 20-fold magnifier to define epidermal types (ET). These types are supposed to be confirmed due to their spectral signature by statistical classification. At the given magnification, we identified five ETs, bladder cells, hairs, flat epidermal cell surface (in the following, known as smooth), convex to papillary epidermal cell surface (in the following, known as rough) and waxes, and assembled them into groups (Figure 1). For each ET, we selected five species, across multiple genera, and ten individuals of each species to measure spectral signatures. 
Table 1. Examined species, their assigned epidermal type and their subfamilies.

\begin{tabular}{|c|c|c|}
\hline Epidermal Type (ET) & Species & Subfamily \\
\hline \multirow{10}{*}{ Bladder cells } & Drosanthemum curtophyllum & \multirow[b]{2}{*}{ Ruschioideae } \\
\hline & L. Bolus NM & \\
\hline & Drosanthemum archeri & \multirow{2}{*}{ Ruschioideae } \\
\hline & L. Bolus NM & \\
\hline & Mesembryanthemum crystallinum & \multirow{2}{*}{ Mesembryanthemoideae } \\
\hline & Linnaeus & \\
\hline & Delosperma vogtsii & \multirow{2}{*}{ Ruschioideae } \\
\hline & L. Bolus NM & \\
\hline & Trichodiadema rupicola & \multirow{2}{*}{ Ruschioideae } \\
\hline & L. Bolus NM & \\
\hline \multirow{10}{*}{ Hair cover } & Gibbaeum shandii & \multirow{2}{*}{ Ruschioideae } \\
\hline & N. E. Brown GC & \\
\hline & Cheiridopsis purpurea & \multirow{2}{*}{ Ruschioideae } \\
\hline & L. Bolus NM & \\
\hline & Braunsia apiculata & \multirow{2}{*}{ Ruschioideae } \\
\hline & (Kensit)L. Bolus & \\
\hline & Juttadineteria albata & \multirow{2}{*}{ Ruschioideae } \\
\hline & (L. Bolus) L. Bolus & \\
\hline & Odontophorus marlothii & \multirow{2}{*}{ Ruschioideae } \\
\hline & N. E. Brown GC & \\
\hline \multirow{10}{*}{ Rough } & Neohenricia spiculata & \multirow[b]{2}{*}{ Ruschioideae } \\
\hline & S. A. Hammer CSJ & \\
\hline & Hereroa puttkameriana & \multirow{2}{*}{ Ruschioideae } \\
\hline & (Dinter \& A. Berger) Dinter \& Schwantes & \\
\hline & Nananthus aloides & \multirow{2}{*}{ Ruschioideae } \\
\hline & (Haworth) Schwantes GF & \\
\hline & Rhombophyllum dolabriforme & \multirow[b]{2}{*}{ Ruschioideae } \\
\hline & (Linnaeus) Schwantes GF & \\
\hline & Stomatium bolusiae & \multirow{2}{*}{ Ruschioideae } \\
\hline & Schwantes MDK & \\
\hline \multirow{10}{*}{ Smooth } & Glottiphyllum longum & \multirow[b]{2}{*}{ Ruschioideae } \\
\hline & (Haworth) N. E. Brown & \\
\hline & Malotigena frantiskae-niederlovae & \multirow{2}{*}{ Ruschioideae } \\
\hline & Niederle & \\
\hline & Aptenia haeckeliana & \multirow{2}{*}{ Mesembryanthemoideae } \\
\hline & (A. Berger) Bittrich ex Gerbaulet & \\
\hline & Schlechteranthus hallii & \\
\hline & L. Bolus & Ruschioideae \\
\hline & Bergeranthus scapiger & \\
\hline & (Haworth) Schwantes & Ruschioideae \\
\hline & Malephora purpurea-crocea & \\
\hline & (Haworth) Schwantes GF & Ruschioideae \\
\hline & Oscularia steenbergensis & \\
\hline & (L. Bolus) H. E. K. Hartmann Bradleya & Ruschioideae \\
\hline & Scopelogena verruculata & \\
\hline Wax cover & (Linnaeus) L. Bolus & Ruschioideae \\
\hline & Amphibolia succulent & \\
\hline & (L.Bolus) H. E. K. Hartmann Bradleya & Ruschioideae \\
\hline & Enarganthe octonaria & \\
\hline & (L. Bolus) N. E. Brown GC & Ruschioideae \\
\hline
\end{tabular}



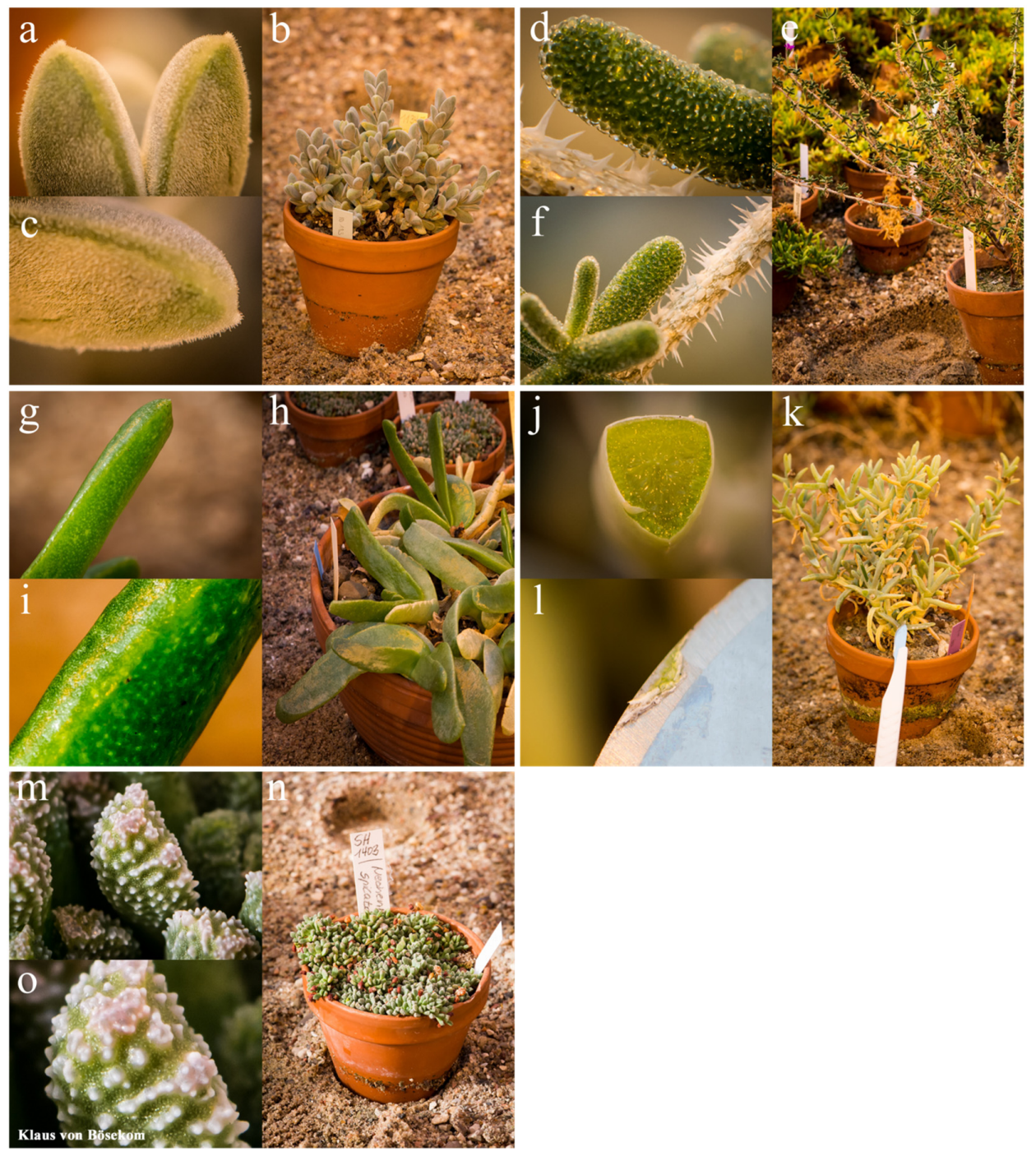

Figure 1. Pictures of the five epidermal types; each group is subdivided into two detailed photos and one photo of the plant's habitus. (a,b,c) Braunsia apiculata, hairs; $(\mathbf{d}, \mathbf{e}, \mathbf{f})$ Drosanthemum archeri, bladder cells; (g,h,i) Glottiphyllum longum; smooth; $(\mathbf{j}, \mathbf{k}, \mathbf{l})$ Malephora purpurea-crocea, wax. The detailed photo in (1) is showing the blade of a scalpel used to abrade the wax layer, which Malephora purpurea-crocea deposits on its leaf surface. (m,n,o) Neohenricia spiculata, rough. All photographs were taken by Klaus von Bösekom with an AF-S VR Micro-Nikkor 105 mm 1:2, 8G IF-ED built by Nikon.

\subsection{Hyperspectral Data Collection}

We recorded spectral signatures using an ASD plant probe attached to an ASD Field-Spec ${ }^{\circledR}$ $4 \mathrm{Hi}$-Res spectrometer. The spectrometer measures the spectral region from $350 \mathrm{~nm}-2500 \mathrm{~nm}$ with a spectral sampling interval of $1.4 \mathrm{~nm}$ in the range of 350-1000 nm and $1.1 \mathrm{~nm}$ until $2500 \mathrm{~nm}$, resulting in a total number of 2151 bands. Before each measurement, the spectrometer was calibrated with a Zenith LiteTM Diffuse Reflectance Target, $95 \%$, from SphereOptics ${ }^{\circledR}$. The calibration was done initially as soon as the spectrometer reached operating temperature and afterwards every $15 \mathrm{~min}$. Flowering pots with the test object were positioned in a cardboard box (Figure 2) lined with black microcellular rubber. Initial experiments showed that this kind of rubber absorbs radiation very well in the range of the measured wavelengths (see Supplementary Materials Figure S1 for a sample spectrum). Lining the nearby environment with micro-cellular rubber (Figure 2a,d) helped to reduce diffuse light reflection and scattering, thus allowing for clean spectra with low noise. 


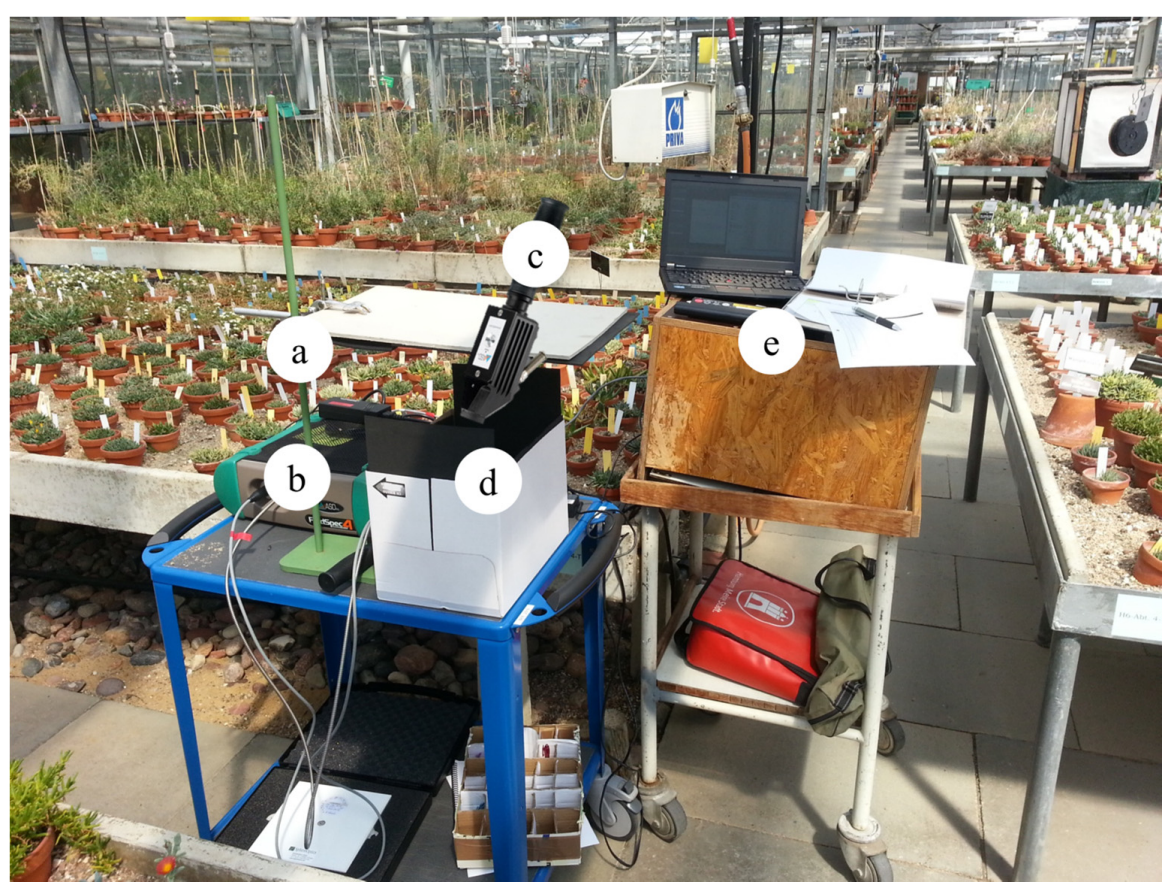

Figure 2. Overview of the applied measuring arrangement in the greenhouse at the botanical garden of Hamburg. The height-adjustable cover (a) and the cardboard box are lined with black microcellular rubber to reduce the albedo during the measurement. A spectrometer (b) is placed on a trolley, and the flowering pots were positioned on the bottom of the cardboard box. A fiber optic cable is located at the front panel of the spectrometer and leads to the plant probe (c). The plant probe that was used during the experiment is placed between the cardboard box (d) and the spectrometer. The plant probe is illustrated above the cardboard box to emphasize that we measured all samples inside this box and applied the probe from above, in order to have direct physical contact with the sampled leaves. A notebook computer (e) was connected with the spectrometer to visualize and store the results of the measurement.

For data collection, either three different leaves (if the leaves were large enough to cover the light path entrance) or three randomly-selected piles of leaves were measured. For the leaf piles, multiple leaves were pressed against each other to obtain a dense area to cover the light path entrance completely. We always positioned the light path entrance in a way that the sampled leaves had physical contact with the elevated frame of the glass panel. We tried not to maintain the contact for too long because of the raised temperature. However, within one measurement, the temperature difference had no impact for us. Five internal repetitions (IR) per measurement were chosen for later averaging. In total, 750 spectra (10 individuals $\times 5$ species $\times 3$ measures $\times 5 \mathrm{IR}=750$ spectra) per ET were measured.

\subsection{Data Preprocessing}

The raw data received were converted from radiance to reflectance data with the ViewSpecPro software provided by the manufacturer of the ASD. In order to identify outlier spectra, all spectra of each species were plotted, and obviously, deviating spectra were deleted manually. The spectral regions from $350 \mathrm{~nm}-400 \mathrm{~nm}$ and from $2400 \mathrm{~nm}-2500 \mathrm{~nm}$ were removed because they primarily consisted of stochastic noise. The dataset collected for all species was averaged per individual. The resulting spectral library contained 10 spectra per species and 50 spectra per ET, totaling up to 500 spectra. We deleted one outlier spectrum for the ET smooth and one for wax. Further preprocessing was applied to prepare the spectra for classification. 


\subsubsection{Jump Correction}

We corrected two shifts in each spectral signature. They originated from the construction of the different detector fields of the sensor. All spectra exhibited such shifts at $1000 \mathrm{~nm}$ and $1800 \mathrm{~nm}$. These irregularities, also called "jumps", could be detected by a classification algorithm as a relevant feature, thus negatively influencing classification. Therefore, jumps were corrected using a multiplicative jump correction algorithm [35].

\subsubsection{Standard Normal Variate Transformation}

Standard normal variate (SNV) transformation is a typical preprocessing step in order to homogenize spectra. Basically, the mathematical transformation, SNV, is used to correct scatter effects in spectra [36,37]. First, each spectrum is centered on zero and afterwards scaled by the standard deviation \pm 1 . However, as the aim of our study was to exploit heterogeneity between the groups, we wanted to test whether SNV transformation could improve our classification. Thus, we produced an additional SNV processed spectral library.

\subsection{Classification}

To confirm the visually-determined ETs, we applied a partial least squares discriminant analysis (PLS-DA) with the R package "DiscriMiner" [38]. PLS-DA is a commonly-applied algorithm for classifying spectral data [39]. In order to test if the classification quality varied for different regions, we tested subsets between $400 \mathrm{~nm}$ and $2400 \mathrm{~nm}$. The PLS-DA was applied on a full spectrum $(400 \mathrm{~nm}-2400 \mathrm{~nm})$, on the VIS region $(400 \mathrm{~nm}-760 \mathrm{~nm})$, on the NIR region $(761 \mathrm{~nm}-1100 \mathrm{~nm})$, on the SWIR I region (1101 nm-1800 nm) and on the SWIR II region (1801 nm-2400 nm). These regions are typical subsets of the whole spectra [40]. To test if distinct bands had a greater impact on the classification than others, we calculated the variable importance in the projection (VIP) score [41,42]. The larger the VIP value, the more important the predictor is for classifying the response [39].

\subsubsection{Partial Least Squares Discriminant Analysis}

PLS was not originally designed as a tool for statistical discrimination. It is used routinely for regression and is usually applied when there are more predictor variables than observations $[43,44]$. This makes PLS highly suitable for high-dimensional data, e.g., chemometric or hyperspectral data. For each response variable $y_{k}$, a regression model on the $\mathrm{X}$-components is expressed as:

$$
y_{k}=\sum_{h=1}^{m}\left(X w_{h}^{*}\right) c_{h}+e=X W^{*} c+e,
$$

$w_{h}^{*}$ is a $\mathrm{p}$ dimension vector ( $p=$ number of parameters) containing the weights given to each original variable in the $\mathrm{k}$-th component, and $c_{h}$ is the regression coefficient of $y_{k}$ on the h-th X-component variable [45]. PLS-DA is an extension of the PLS regression by a linear discriminant analysis [46] to be used for classification purposes.

The variable importance in the projection (VIP) scores obtained by the PLS are an important measure of each explanatory predictor [41]. The VIP score for the $j$-th variable can be calculated by:

$$
V I P_{j}=\left\{p \sum_{h=1}^{m} \sum_{k} \frac{R^{2}\left(y_{k}, t_{h}\right) w_{h j}^{2}}{\sum_{h=1}^{m} \sum_{k} R^{2}\left(y_{k}, t_{h}\right)}\right\}^{\frac{1}{2}}
$$

For each $\mathrm{j}$-th predictor variable $\mathrm{j}=1, \mathrm{p}$, where $R^{2}(\mathrm{a}, \mathrm{b})$ stands for the squared correlation between items in vector a and vector $\mathrm{b} ; t_{h}=X_{h}-1 w_{h}$, where $X_{h}-1$ is the residual matrix in the regression of $\mathrm{X}$ on component $t_{1}, \ldots, t_{h}-1$; and $w_{h}$ is a vector of norm 1 . Note that $w_{h j}^{2}$ measures the contribution of each variable $\mathrm{j}$ to the h-th PLS component [45]. Thus, VIP $P_{j}$ quantifies the influence on the response 
of each variable summed over all components and categorical responses relative to the total sum of squares of the model. As a rule of thumb, any independent variable with a VIP coefficient smaller than 0.8 had no impact on the classification [47].

\subsubsection{Validation}

To validate the classification results, we chose two strategies; firstly, a training, test dataset, and, secondly, a cross-validation (CV) approach. The spectral database was split $80: 20$ into a training dataset and a test dataset. The spectral databases contained 50 spectra for each ET, leaving 40 spectra for the training dataset and ten spectra for the test dataset. We deleted one averaged outlier spectrum for the ET smooth and one for wax, resulting in only 49 spectra for each of the two groups. A leave-one-out cross-validation (LOO-CV) was applied on the PLS-DA. LOO-CV is a special case of the $\mathrm{k}$-fold $\mathrm{CV}$ where $\mathrm{k}=\mathrm{N}$, while $\mathrm{N}$ is the number of observations [48]. We used 50 spectra for each group, resulting in $\mathrm{k}=50$.

\subsubsection{Accuracy Assessment}

Following classification, performance metrics were chosen. The simplest metric is the overall accuracy $(\mathrm{OA})$ or error rate. OA reflects the agreement between the observed and predicted classes and has the most direct interpretation. However, it does not provide information about the origin of an error [39]. Thus, we also calculated the Kappa statistic [49]. Kappa can take on values between -1 and 1; a value of 0 implies no agreement between the observed and predicted classes, while a Kappa of 1 indicates perfect concordance of the model prediction and the observed classes. A negative Kappa indicates that the prediction is in the opposite direction of the truth, but negative values for Kappa are not very common [39]. Landis and Koch [50] first defined the following standards for the strength of agreement for kappa coefficients: $\leqslant 0$ = poor; $0.01-0.20=$ slight; $0.21-0.40=$ fair; $0.41-0.60=$ moderate; $0.61-0.80$ = substantial; and $0.81-1=$ almost perfect. As class-specific metrics, we further calculated producer accuracy (PA) and user accuracy (UA) [51]. PA is the number of correctly-classified spectra for a class divided by the reference number of that class and, thus, represents the accuracy of the classification for a specific class. UA divides the number of correctly-classified spectra in a class by the total number of spectra within that class. A high UA means that spectra within that class can be reliably classified as belonging to that class. User accuracy is often termed to be a measure of reliability, which can be also interpreted as the agreement between repeated measurements within a class [52].

\section{Results}

\subsection{Partial Least Squares Discriminant Analysis: Classification}

Out of twenty method combinations, we found that a cross-validated PLS-DA without a preceding SNV transformation, applied on a full spectrum, delivered a Kappa value of 0.90 (Table 2), indicating an almost perfect concordance of the model prediction and the observed classes [50]. The second best model had a Kappa value of 0.77; here, we applied a test validation, including an SNV transformation applied on a full spectrum. Both models still indicate the substantial concordance of the model prediction and the observed classes.

Across all approaches, the overall accuracy OA ranged from 0.21-0.92. Within the training validation dataset, it ranged from $0.21-0.81$, and within the cross validation dataset, it ranged from 0.34-0.92. The Kappa range across all approaches was 0.01-0.90. Within the training validation dataset, Kappa ranged from 0.01-0.77 and within the cross-validation from 0.17-0.90. By calculating the accuracies across all approaches to compare the tested subsets, it becomes obvious that the regions VIS $(\mathrm{OA}=0.52, \mathrm{Kappa}=0.40), \mathrm{NIR}(\mathrm{OA}=0.41, \mathrm{Kappa}=0.27)$ and SWIR I $(\mathrm{OA}=0.30, \mathrm{Kappa}=0.13)$ were outperformed by the accuracies of the full spectrum $(\mathrm{OA}=0.72$, Kappa $=0.66)$ and SWIR II $(\mathrm{OA}=0.64$, Kappa $=0.55)$. The influence of an SNV transformation on our classification can be 
judged by comparing, again, the average accuracies for SNV (OA = 0.55, Kappa $=0.43)$ and non-SNV $(\mathrm{OA}=0.49$, Kappa $=0.36)$.

Table 2. Results deriving from a PLS-DA applied on the spectral database. The summary of the accuracy assessment statistics is displayed, including the best classification result written in bold.

\begin{tabular}{cccccccc}
\hline SNV/no SNV & Segment & Validation & OA & \multicolumn{2}{c}{$\mathbf{9 5 \%}$ CI } & $p$-Value & Kappa \\
\hline SNV & Full & Training & 0.81 & 0.67 & 0.91 & $<0.05$ & 0.77 \\
SNV & Full & Cross & 0.55 & 0.48 & 0.61 & $<0.05$ & 0.44 \\
SNV & VIS & Training & 0.54 & 0.39 & 0.69 & $<0.05$ & 0.43 \\
SNV & VIS & Cross & 0.52 & 0.46 & 0.58 & $<0.05$ & 0.40 \\
SNV & NIR & Training & 0.52 & 0.37 & 0.67 & $<0.05$ & 0.40 \\
SNV & NIR & Cross & 0.50 & 0.44 & 0.57 & $<0.05$ & 0.38 \\
SNV & SWIR I & Training & 0.21 & 0.10 & 0.35 & & 0.01 \\
SNV & SWIR I & Cross & 0.37 & 0.31 & 0.43 & $<0.05$ & 0.21 \\
SNV & SWIR II & Training & 0.67 & 0.52 & 0.80 & $<0.05$ & 0.59 \\
SNV & SWIR II & Cross & 0.77 & 0.71 & 0.82 & $<0.05$ & 0.71 \\
no SNV & Full & Training & 0.60 & 0.45 & 0.74 & $<0.05$ & 0.51 \\
no SNV & Full & Cross & $\mathbf{0 . 9 2}$ & $\mathbf{0 . 8 8}$ & $\mathbf{0 . 9 5}$ & $<0.05$ & $\mathbf{0 . 9 0}$ \\
no SNV & VIS & Training & 0.46 & 0.31 & 0.61 & $<0.05$ & 0.32 \\
no SNV & VIS & Cross & 0.54 & 0.48 & 0.60 & $<0.05$ & 0.43 \\
no SNV & NIR & Training & 0.29 & 0.17 & 0.44 & & 0.11 \\
no SNV & NIR & Cross & 0.34 & 0.28 & 0.40 & $<0.05$ & 0.17 \\
no SNV & SWIR I & Training & 0.27 & 0.15 & 0.42 & & 0.09 \\
no SNV & SWIR I & Cross & 0.35 & 0.29 & 0.41 & & 0.19 \\
no SNV & SWIR II & Training & 0.56 & 0.41 & 0.71 & $<0.05$ & 0.45 \\
no SNV & SWIR II & Cross & 0.55 & 0.48 & 0.61 & $<0.05$ & 0.44 \\
\hline
\end{tabular}

OA, overall accuracy; CI, confidence interval; Full, full spectrum; VIS, visible spectral wavelength; NIR, near infrared spectral wavelength; SWIR I, short wave infrared spectral wavelength Section I; SWIR II, short wave infrared spectral wavelength Section II; T, training validation; C, cross validation; SNV, standard normal variate transformation applied; no $\mathrm{SNV}$, no standard normal variate transformation applied.

Averaged spectral signatures per group (Figure 3) show that hairs and waxes differ strongly from the other groups in the VIS region, in particular, they have a higher reflectance around $550 \mathrm{~nm}$. Bladder cells and the rough texture show similar pattern in the spectral region from $850 \mathrm{~nm}-1100 \mathrm{~nm}$, while the other groups show very similar spectral patterns. Bladder cells also display an interesting feature of increased reflection around $1700 \mathrm{~nm}$. Hairs generally have, over the whole spectrum, a high reflectance, while the smooth texture generally has the lowest reflectance across the whole spectrum (except in the VIS region). A clear ranking of spectra according to reflectance was not possible, because no spectrum is always higher than any other. Confusion matrices for the best two models (Table 3) revealed that the ETs bladder cells and waxes had in both datasets high user accuracies (UA), while their producer accuracies (PA) were moderate. Generally weak were the classes smooth and rough. Both had the lowest UA, depending on the dataset. The lowest absolute UA value had smooth $(67 \%)$ in the test dataset. PA was lowest for smooth $(80 \%)$ in the cross-validated dataset, while wax had the lowest PA in the test dataset (75\%). The cross-validated dataset generally had higher accuracy values than the test dataset. In terms of PA, bladder cells, hairs and wax cover were consistently, highly accurate for the two different methods (Table 3), while rough and smooth often got mixed up, but also with the class hairs. Across the two methods, consistently high UA values are only found for hairs and bladder cells (Table 3). The other classes differ between the two methods with the lowest values found for smooth in the CV/no SNV and wax for the training/SNV confusion matrix. We checked the robustness of the PLS-DA models by comparing the ranking of the different method combinations presented in Table 3 based on the Kappa values. We inspected the rankings separately for the two validation steps, i.e., $\mathrm{CV}$ and training dataset. The order of the method combinations seemed relatively robust with respect to the subset used (full versus different wavelength regions). 
However, the effect of SNV transformation changed more often, in particular within the first ranks for each method. Hence, we can say that full spectra and SWIR II worked equally well in both methodologies, yet depending on the SNV transformation, the method combinations got ranked differently. With this unsteadiness based on the transformation, we decided to compare the confusion matrices for the best model of each validation technique. For a complete overview of the accuracy assessment, see the Supplementary Materials (Table S1).

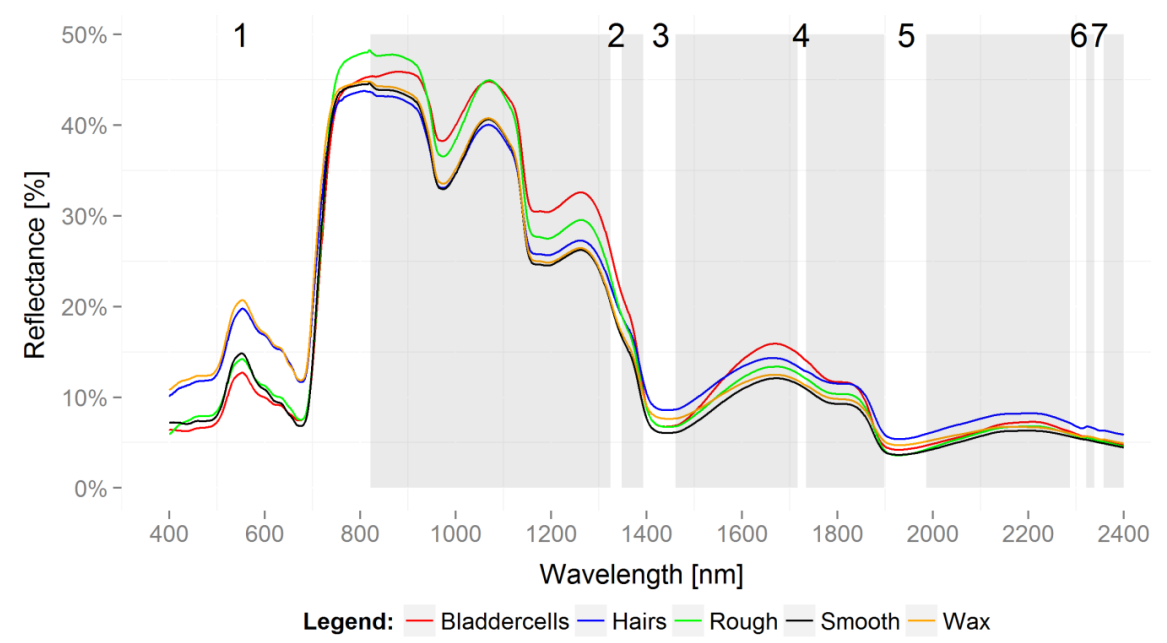

Figure 3. Reflectance spectra. The image displays five averaged spectra that representing each functional group. The spectral regions (1-7), revealed by variable importance for projection (VIP) analysis, are highlighted in the white and unshaded areas. The numeration, $1-7$, can be found directly above the center of each region.

Table 3. Confusion matrices for the best two models, each recorded over the full spectrum. The upper table belongs to the cross-validated and no SNV transformation, the lower table to the test dataset and SNV transformation. The columns denote observed (ground truth) cases and the rows predicted (classification) cases. For each dataset, the user's and producer's accuracies are indicated.

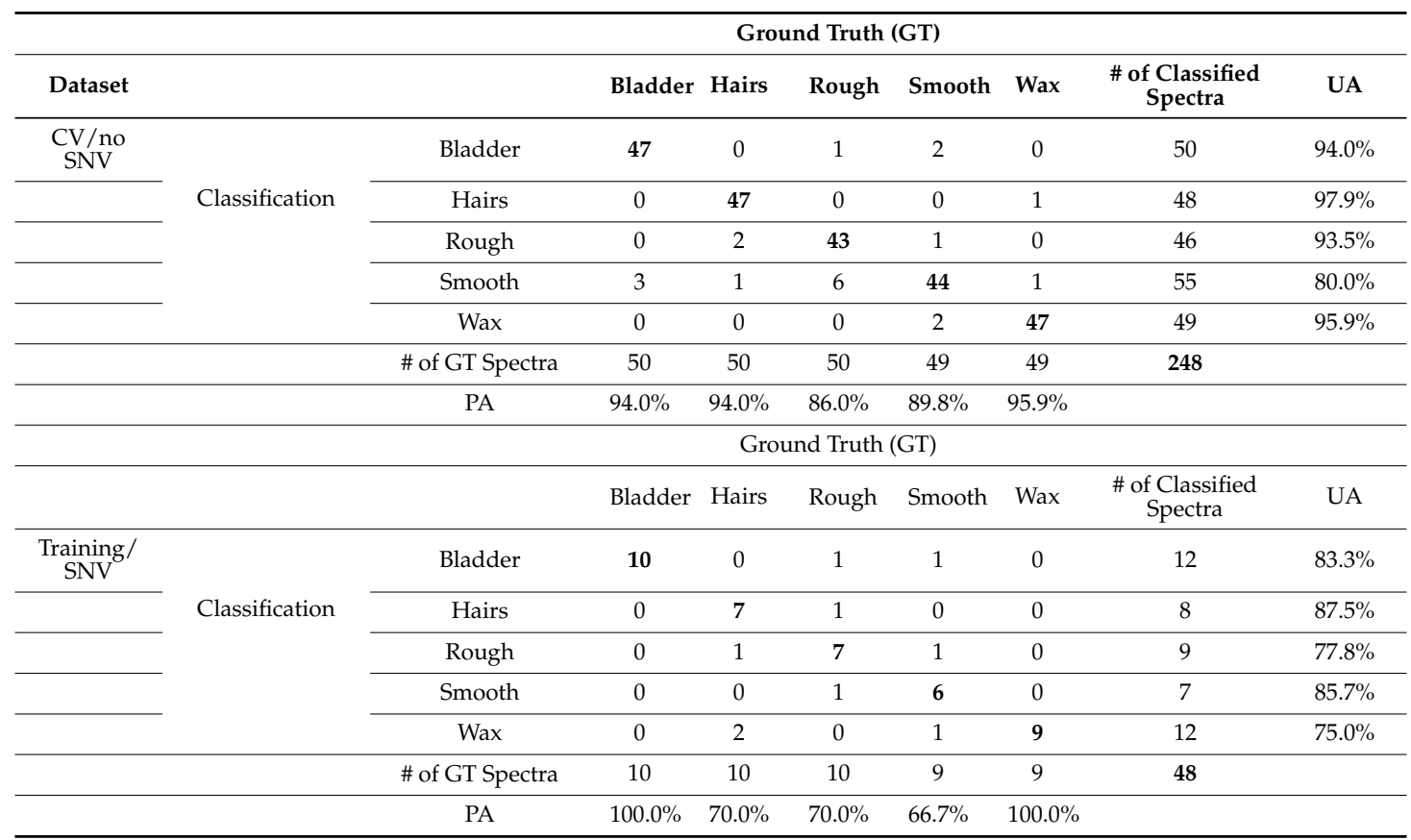

$\mathrm{CV}$, cross-validation; Training, training validation; $\mathrm{P}$, predicted; $\mathrm{O}$, observed; SNV, standard normal variate transformation applied; no SNV, no standard normal variate transformation applied. 


\subsection{Variable Importance for Projection}

To test if distinct bands had a greater impact on the classification than others, we calculated the VIP score. We modified the suggestion of Leung [47] to delete VIP values smaller than 0.8; we considered VIP values $>1$ to be significant. The calculation of the VIPs revealed seven spectral regions of increased importance for the classification (Figure 3). One large region covers the whole VIS region, including a small bit of the NIR region $(400 \mathrm{~nm}-820 \mathrm{~nm})$. Regions $2(1325 \mathrm{~nm}-1347 \mathrm{~nm}), 3$ (1394 $\mathrm{nm}-1460 \mathrm{~nm}), 4(1717 \mathrm{~nm}-1733 \mathrm{~nm}), 5(1899 \mathrm{~nm}-1985 \mathrm{~nm}), 6(2288 \mathrm{~nm}-2320 \mathrm{~nm})$ and $7(2339 \mathrm{~nm}-2356$ $\mathrm{nm}$ ) all lie beyond the NIR region, while Regions 3 and 5 are located in the water absorption regions.

\section{Discussion}

The classification of our spectral signatures generally approved the visually-defined epidermal types (ET) as indicated by the high Kappa values. That implies species grouped by their epidermal structures (ES), like hairs, waxes; bladder cells, etc. are indeed spectrally separable; or in other words, ETs are similar in spectral properties within an ET, but do significantly differ between other ETs. The fact that this pattern also holds across species from different genera within one ET supports the idea of Ustin and Gamon [31] that optical types could be a new form of grouping species with a more functional interpretation.

Our findings carry weight because they confirm and expand the findings of earlier studies regarding the effects of ES on spectral signatures $[9,10,19,53]$. We identified five different functional groups based on their ES: hairs, bladder cells, rough and smooth textures and epicuticular waxes. Other studies defined similar groups, but there might have been differences in the interpretation of epidermal structures. ES of succulents were frequently described by botanists; e.g., Opel and Hammer [54] characterized three different epidermal types: trichrome/papillae, bladder cells and stomata alone for the genus Conophytum with numerous subdivisions. Ihlenfeldt and Hartmann [21] defined xeromorphic epidermis types for succulents of the Mesembryanthemaceae. This concept was advanced by Jürgens [23] and Niesler [24]. Yet, they did not make any spectral measurements. Tanner and Eller [14] analyzed the spectral signatures of the epidermal structures of the Mesembryanthemaceae, i.e., bladder cells and smooth leaf surfaces. However, they did not find any conspicuous differences in the spectral signatures. Our averaged spectra per ET (Figure 3) show a similar pattern for bladder cells and smooth surfaces in the VIS region that were studied by Tanner and Eller [14]. However, bladder cells clearly differ from apparently smooth surfaces in the spectral region between $1600 \mathrm{~nm}$ and $1700 \mathrm{~nm}$, a spectral region that was not accessible in the days of Tanner and Eller. Hence, it can be assumed that our findings provide an extension of previous findings.

Leaf pubescence increases the reflectance of global radiation and is very effective between $400 \mathrm{~nm}$ and $700 \mathrm{~nm}$ [9]. Besides affecting reflectance, hairs on leaf surfaces help to diminish transpiration and support thermal convection processes [10]. Eller and von Willert [10,19] both stated that hairs have no effect on spectral regions larger than $750 \mathrm{~nm}$, though we found six spectral regions beyond $750 \mathrm{~nm}$ where hairs actually had an impact on the spectral classification. In fact, our ET hairs had, except from $750 \mathrm{~nm}-1200 \mathrm{~nm}$, constantly high reflectance values compared to other ETs. Epicuticular waxes on leaves are, like hairs, able to increase the spectral reflectance between $400 \mathrm{~nm}$ and $750 \mathrm{~nm}$ [11]. Furthermore, enclosed oxalate crystals inside of wax layers can amplify the reflection of photons up to $33 \%[10,21]$. Another process of leaf surfaces influencing an ecological strategy was shown by Haberland [55]. He found that papillae have a lens effect on incoming photons. Tanner and Eller [14] and von Willert [19] specified this and explained that due to the lens effect, photons are able to reach assimilation tissues located in deeper cell layers of leaves. Lastly, plants may exhibit papillae on their leaf surfaces to form a rough epidermal structure; as a consequence, they are able to modify the convective energy transfer by producing Reynolds' turbulences $[10,19,56]$. That bladder cells also interfere with photons was shown by Tanner and Eller [14]. This time, the reflectance between $400 \mathrm{~nm}$ and $1200 \mathrm{~nm}$ was lowered, and the absorption was increased. 
All of these examples emphasize a strong connection between spectral signatures and plants' epidermal structures, which represent different adaptions of plants to their environment. However, these examples also just focus on the IR (infra-red) region of the electromagnetic spectrum. Today, it is well known that spectral responses of the IR region are mainly caused by plant pigments of the palisade mesophyll and leaf cell structures. Beyond this region $(1300 \mathrm{~nm}-2600 \mathrm{~nm})$, it is known that the plant's water content has a great effect on the reflected signature [40]. We are happy to confirm reflection patterns in the IR region, but it is even more gratifying that our applied VIP calculation revealed the already mentioned bands, which supports our classification of epidermal types (ETs). This finding shows that the bands beyond the IR region might contain not just information regarding leaf water content, but also regarding leaf surface structures.

Our classification had also several weaknesses. First of all, biochemical properties or varying leaf angles during the measurement could have an impact on the spectral response, as well, which were not taken into account in this study. Our focus was to show that, basically, one can separate ETs spectrally from each other and put them into categories. Still, the biochemical components would be worthwhile to include in a future multivariate regression model combined with functional groupings as our ETs. This would better allow discerning the different effects of biochemical and biophysical properties. It would also be useful to test the regions, detected by the VIP calculation, for a classification to increase accuracies. Again, the spectral differences between the groups cannot be explained by the reflectance of epidermal structures alone. Further studies are required to understand the proportion to which ES have an impact on the detected regions. A new technology called hyperspectral microscopy has a high potential for disentangling the biochemical and biophysical effects on spectral signatures of leaves [57]. It combines high resolution microscopy, even on the nanoscale, with hyperspectral resolution from $400 \mathrm{~nm}$ to approximately $1000 \mathrm{~nm}$.

In addition, we had problems classifying the group "smooth", which had the lowest user accuracy. Initially, we classified the ETs with a 20-fold magnifier, but the spectral classification was able to detect details that we could not detect with the magnifier. Roberts [58] stated that spectral features change with the scale of the measurement. At each larger scale, new features are included in the measurements that were either absent or of minor importance at lower scales. Hartmann $[59,60]$ summarized properties of the family Aizoaceae and described epidermal structures of the plants we investigated in this study. Having this source, we once more compared the plants of the group "smooth", Glottiphyllum longum, Malotigena frantiskae-niederlovae, Aptenia haeckeliana, Schlechteranthus hallii and Bergeranthus scapiger, with the classification by Hartmann [59,60], who describes Glottiphyllum longum and Aptenia haeckeliana as exhibiting inconspicuous bladder cells. Schlechteranthus hallii and Bergeranthus scapiger are described to have a wax layer besides slightly elevated cells (more or less rough) on the leaf surface. These descriptions conceivably explain why the class smooth could not be perfectly classified as a single ET. However, the species were correctly classified into other respective groups, i.e., bladder cells, rough and smooth (cf. Table 2) groups, in which these plants belong instead. The positive aspect of this mistake is that the spectral classification corrected our initial classification and, therefore, emphasized the usefulness of our classification.

\section{Conclusions}

With this study, we aimed at contributing to the concept of plant functional classification, i.e., the "optical types" by Ustin and Gamon [31], which directly links ecological pattern and remotely-sensed spectral data. We demonstrated that five different functional types of epidermal leaf structures sampled across 25 species from a single plant family could be distinguished based on leaf spectral signatures. We found six spectral regions, all beyond $1100-1300 \mathrm{~nm}$, that had a significant impact on the classification of leaf epidermal structures according to the variable of importance (VIP) measure. Epidermal structures, like bladder cells, hairs and waxes, were accurately classified (producer accuracy between $70 \%$ and $100 \%$ ), while rough and smooth structures had lower classification rates (producer accuracy between $66 \%$ and $89 \%$ ). In particular, we could demonstrate 
that the morphological pattern can translate directly into spectral signals. However, the effects of biochemical constituents, such as pigments, which are also known to influence spectral signatures, were not analyzed in this study. Future studies should take into account biophysical, i.e., leaf epidermal structures and biochemical information for discriminating plant species based on leaf spectral signals.

Acknowledgments: We thank Katrin Baumgärtner for taking care of the Aizoaceae living collection and her advice on selecting appropriate plants, Ute Schmiedel and Ingeborg Niesler for their knowledge on epicuticular structures of Aizoaceae and Klaus von Bösekom for taking the pretty photos. Funding was provided by DFG (QUEEN, OL 417/1-1, TH 1295/4-1).

Author Contributions: André Große-Stoltenberg assisted in setting up the experiments regarding the handheld spectrometer and in processing the spectral data. Norbert Jürgens contributed to the manuscript and granted access to the living collection of Aizoaceae. Jens Oldeland conceived of the idea of the study, edited the manuscript and designed the statistical analysis. Rene Hans-Jürgen Heim conducted the experiments and the statistical analysis, performed the literature research and wrote the manuscript.

Conflicts of Interest: The authors declare no conflict of interest.

\section{References}

1. Sims, D.A.; Gamon, J.A. Relationships between leaf pigment content and spectral reflectance across a wide range of species, leaf structures and developmental stages. Remote Sens. Environ. 2002, 81, 337-354. [CrossRef]

2. Blackburn, G.A. Hyperspectral remote sensing of plant pigments. J. Exp. Bot. 2007, 58, 855-867. [CrossRef] [PubMed]

3. Hellmann, C.; Grosse-Stoltenberg, A.; Laustro, V.; Oldeland, J.; Werner, C. Retrieving nitrogen isotopic signatures from fresh leaf reflectance spectra: Disentangling delta $\delta^{15} \mathrm{~N}$ from biochemical and structural leaf properties. Front. Plant Sci. 2015, 6, 307. [CrossRef] [PubMed]

4. Asner, G.P.; Martin, R.E.; Tupayachi, R.; Anderson, C.B.; Sinca, F.; Carranza-Jimenez, L.; Martinez, P. Amazonian functional diversity from forest canopy chemical assembly. Proc. Natl. Acad. Sci. USA 2014, 111, 5604-5609. [CrossRef] [PubMed]

5. Lehmann, J.R.K.; Grosse-Stoltenberg, A.; Romer, M.; Oldeland, J. Field spectroscopy in the vnir-swir region to discriminate between mediterranean native plants and exotic-invasive shrubs based on leaf tannin content. Remote Sens. 2015, 7, 1225-1241. [CrossRef]

6. Kalacska, M.; Bohman, S.; Sanchez-Azofeifa, G.A.; Castro-Esau, K.; Caelli, T. Hyperspectral discrimination of tropical dry forest lianas and trees: Comparative data reduction approaches at the leaf and canopy levels. Remote Sens. Environ. 2007, 109, 406-415. [CrossRef]

7. Sims, D.A.; Gamon, J.A. Estimation of vegetation water content and photosynthetic tissue area from spectral reflectance: A comparison of indices based on liquid water and chlorophyll absorption features. Remote Sens. Environ. 2003, 84, 526-537. [CrossRef]

8. Da Luz, B.R. Attenuated total reflectance spectroscopy of plant leaves: A tool for ecological and botanical studies. New Phytol. 2006, 172, 305-318. [CrossRef] [PubMed]

9. Ehleringer, J.R.; Bjorkman, O. Pubescence and leaf spectral characteristics in a desert shrub, encelia farinosa. Oecologia 1978, 36, 151-162. [CrossRef]

10. Eller, B.M. Epidermis and the spectral properties of plant-surfaces. Ber. Deut. Bot. Ges. 1985, 98, 465-475.

11. Eller, B.M.; Willi, P. The significance of leaf pubescence for the absorption of global radiation by tussilago farfara 1. Oecologia 1977, 29, 179-187. [CrossRef]

12. Ehleringer, J.R.; Mooney, H.A. Leaf hairs: Effects on physiological activity and adaptive value to a desert shrub. Oecologia 1978, 37, 183-200. [CrossRef]

13. Mulroy, T.W. Spectral properties of heavily glaucous and non-glaucous leaves of a succulent rosette-plant. Oecologia 1979, 38, 349-357. [CrossRef]

14. Tanner, V.; Eller, B.M. Epidermis structure and its significance for the optical-properties of leaves of the mesembryanthemaceae. J. Plant Physiol. 1986, 125, 285-294. [CrossRef]

15. Huntjr, E.; Rock, B. Detection of changes in leaf water content using near- and middle-infrared reflectances. Remote Sens. Environ. 1989, 30, 43-54. [CrossRef] 
16. Martin, M.E.; Aber, J.D. High spectral resolution remote sensing of forest canopy lignin, nitrogen, and ecosystem processes. Ecol. Appl. 1997, 7, 431-443. [CrossRef]

17. Martin, M.E.; Newman, S.D.; Aber, J.D.; Congalton, R.G. Determining forest species composition using high spectral resolution remote sensing data. Remote Sens. Environ. 1998, 65, 249-254. [CrossRef]

18. Carter, G.A.; Knapp, A.K. Leaf optical properties in higher plants: Linking spectral characteristics to stress and chlorophyll concentration. Am. J. Bot. 2001, 88, 677-684. [CrossRef] [PubMed]

19. Von Willert, D.J. Life Strategies of Succulents in Deserts: With Special Reference to the Namib Desert; CUP Archive: New York, NY, USA, 1992; p. 372.

20. Myers, N.; Mittermeier, R.A.; Mittermeier, C.G.; da Fonseca, G.A.; Kent, J. Biodiversity hotspots for conservation priorities. Nature 2000, 403, 853-858. [CrossRef] [PubMed]

21. Ihlenfeldt, H.D.; Hartmann, H.E.K. Leaf surfaces in mesembryanthemaceae. In The Plant Cuticle; Cutler, D.F., Alvin, K.L., Price, C.E., Eds.; Academic Press: London, UK, 1982; pp. 397-423.

22. List, T.P. The Plant List (2013). Version 1.1. Available online: http://www.theplantlist.org/ (accessed on 1 May 2014).

23. Jürgens, N. Untersuchungen zur Ökologie sukkulenter Pflanzen des südlichen Afrika. Mitt. Inst. Allg. Bot. Hamburg 1986, 21, 139-365.

24. Niesler, I.M. Untersuchungen zur Ontogenie und zum Bau der Blätter bei Mesembryanthemaceae Fenzl unter besonderer Berücksichtigung der Epidermis. Ph.D. Thesis, Universität Hamburg, Hamburg, Germany, 1998.

25. Clark, M.L.; Roberts, D.A.; Clark, D.B. Hyperspectral discrimination of tropical rain forest tree species at leaf to crown scales. Remote Sens. Environ. 2005, 96, 375-398. [CrossRef]

26. Ghiyamat, A.; Shafri, H.Z.M.; Mandiraji, G.A.; Shariff, A.R.M.; Mansor, S. Hyperspectral discrimination of tree species with different classifications using single- and multiple-endmember. Int. J. Appl. Earth Observ. Geoinf. 2013, 23, 177-191. [CrossRef]

27. Prospere, K.; McLaren, K.; Wilson, B. Plant species discrimination in a tropical wetland using in situ hyperspectral data. Remote Sens. 2014, 6, 8494-8523. [CrossRef]

28. He, Y.; Li, X.; Deng, X. Discrimination of varieties of tea using near infrared spectroscopy by principal component analysis and bp model. J. Food Eng. 2007, 79, 1238-1242. [CrossRef]

29. Edelmann, A.; Diewok, J.; Schuster, K.C.; Lendl, B. Rapid method for the discrimination of red wine cultivars based on mid-infrared spectroscopy of phenolic wine extracts. J. Agric. Food Chem. 2001, 49, 1139-1145. [CrossRef] [PubMed]

30. Rao, N.R.; Garg, P.K.; Ghosh, S.K. Development of an agricultural crops spectral library and classification of crops at cultivar level using hyperspectral data. Precis. Agric. 2007, 8, 173-185. [CrossRef]

31. Ustin, S.L.; Gamon, J.A. Remote sensing of plant functional types. New Phytol. 2010, 186, $795-816$. [CrossRef] [PubMed]

32. Duckworth, J.C.; Kent, M.; Ramsay, P.M. Plant functional types: An alternative to taxonomic plant community description in biogeography? Prog. Phys. Geogr. 2000, 24, 515-542. [CrossRef]

33. Homolova, L.; Maenovsky, Z.; Clevers, J.G.P.W.; Garcia-Santos, G.; Schaeprnan, M.E. Review of optical-based remote sensing for plant trait mapping. Ecol. Complex. 2013, 15, 1-16. [CrossRef]

34. Houborg, R.; Fisher, J.B.; Skidmore, A.K. Advances in remote sensing of vegetation function and traits. Int. J. Appl. Earth Observ. Geoinf. 2015, 43, 1-6. [CrossRef]

35. Dorigo, W.; Bachmann, M.; Heldens, W. AS Toolbox \& Processing of Field Spectra-user's manual; German Aerospace Center, DLR-DFD. Imaging Spectroscopy Group: Wessling, Germany, 2006.

36. Fearn, T.; Riccioli, C.; Garrido-Varo, A.; Guerrero-Ginel, J.E. On the geometry of snv and msc. Chemom. Intell. Lab. Syst. 2009, 96, 22-26. [CrossRef]

37. Barnes, R.J.; Dhanoa, M.S.; Lister, S.J. Standard normal variate transformation and de-trending of near-infrared diffuse reflectance spectra. Appl. Spectrosc. 1989, 43, 772-777. [CrossRef]

38. Sanchez, G.; Determan, C.; Sanchez, M.G. R Package DiscriMiner (Version 0.1-29). Available online: https://cran.r-project.org/web/packages/DiscriMiner/ (accessed on 13 May 2015).

39. Kuhn, M.; Johnson, K. Applied Predictive Modeling; Springer: Berlin, Germany, 2013.

40. Thenkabail, P.S.; Lyon, J.G.; Huete, A. Hyperspectral Remote Sensing of Vegetation; CRC Press: Boca Raton, FL, USA, 2011; p. 766. 
41. Chong, I.G.; Jun, C.H. Performance of some variable selection methods when multicollinearity is present. Chemom. Intell. Lab. Syst. 2005, 78, 103-112. [CrossRef]

42. Wold, S.; Kettaneh, N.; Tjessem, K. Hierarchical multiblock pls and pc models for easier model interpretation and as an alternative to variable selection. J. Chemom. 1996, 10, 463-482. [CrossRef]

43. Wold, S.; Martens, H.; Wold, H. The multivariate calibration problem in chemistry solved by the PLS method. In Matrix Pencils; Kågström, B., Ruhe, A., Eds.; Springer: Berlin, Germany, 1983; pp. 286-293.

44. Barker, M.; Rayens, W. Partial least squares for discrimination. J. Chemom. 2003, 17, 166-173. [CrossRef]

45. Perez-Enciso, M.; Tenenhaus, M. Prediction of clinical outcome with microarray data: A partial least squares discriminant analysis (PLS-DA) approach. Hum. Genet 2003, 112, 581-592. [PubMed]

46. Fisher, R.A. The use of multiple measurements in taxonomic problems. Ann. Eugen. 1936, 7, 179-188. [CrossRef]

47. Leung, K.; Cheong, F.; Cheong, C.; O'Farrell, S.; Tissington, R.; Ou, C.M. A Comparison of Variable Selection Techniques for Credit Scoring. In Proceedings of the 7th International Conference on Computational Intelligence in Economics and Finance, Taiwan, 4 Augest 2008.

48. Efron, B.; Tibshirani, R. Improvements on cross-validation: The 632+ bootstrap method. J. Am. Stat. Assoc. 1997, 92, 548-560.

49. Cohen, J. A coefficient of agreement for nominal scales. Educ. Psychol. Meas. 1960, 20, 37-46. [CrossRef]

50. Landis, J.R.; Koch, G.G. The measurement of observer agreement for categorical data. Biometrics 1977, 33, 159-174. [CrossRef] [PubMed]

51. Story, M.; Congalton, R.G. Accuracy assessment-A users perspective. Photogramm Eng. Remote Sens. 1986, 52, 397-399.

52. Jones, H.G.; Vaughan, R.A. Remote Sensing of Vegetation: Principles, Techniques, and Applications; Oxford University Press: New York, NY, USA, 2010; p. 381.

53. Opel, M.R. Leaf anatomy of conophytum n.E.Br. (aizoaceae). Haseltonia 2005, 11, 27-52. [CrossRef]

54. Opel, M.R.; Hammer, S.A. Conophytum leaf structures. In SA Hammer, Dumpling and His Wife: New Views of the Genus Conophytum; EAE Creative Color Ltd.: Norwich, UK, 2002; pp. 300-321.

55. Haberland, G. Physiologische pflanzenanatomie, Leipzig 1909, IV. Aufl. S 1909, 557, 671.

56. Barthlott, W.; Wollenweber, E. Zur Feinstruktur, Chemie und taxonomischen Signifikanz epicuticularer Wachse und ähnlicher Sekrete. Trop. Subtrop. Pflanzenwelt. 1981, 32, 67.

57. Roth, G.A.; Tahiliani, S.; Neu-Baker, N.M.; Brenner, S.A. Hyperspectral microscopy as an analytical tool for nanomaterials. Wiley Interdiscip. Rev. Nanomed. Nanobiotechnol. 2015, 7, 565-579. [CrossRef] [PubMed]

58. Roberts, D.A.; Ustin, S.L.; Ogunjemiyo, S.; Greenberg, J.; Dobrowski, S.Z.; Chen, J.Q.; Hinckley, T.M. Spectral and structural measures of northwest forest vegetation at leaf to landscape scales. Ecosystems 2004, 7, 545-562. [CrossRef]

59. Hartmann, H.E.K. Illustrated Handbook of Succulent Plants: Aizoaceae A-E; Springer Science \& Business Media: Berlin/Heidelberg, Germany, 2002; p. 456.

60. Hartmann, H.E.K. Illustrated Handbook of Succulent Plants: Aizoaceae F-Z; Springer Science \& Business Media: Berlin/Heidelberg, Germany, 2002; p. 422.

(C) 2015 by the authors; licensee MDPI, Basel, Switzerland. This article is an open access article distributed under the terms and conditions of the Creative Commons by Attribution (CC-BY) license (http://creativecommons.org/licenses/by/4.0/). 